\title{
Helicobacter pylori treatment in the hospital setting: A potential model for developing quality improvement initiatives to prevent missed test results
}

\author{
Nicola L Jones MD FRCPC PhD
}

$H$ elicobacter pylori is an important global cause of peptic ulcer disease and gastric cancer (1). In developed countries, the prevalence of infection is decreasing and there is an emerging concept that this decline in $\mathrm{H}$ pylori may be associated with the development of other diseases such as asthma, esophageal cancer and obesity (2). With the changes in the epidemiology of $\mathrm{H}$ pylori infection, it is important that clinical management guidelines are updated and that physicians implement these updated evidence-based guidelines in their practice.

In the current issue of The Canadian Journal of Gastroenterology, Yogeswaran et al (3) (pages 543-546) determine how well H pylori is being managed in infected adults at a tertiary care centre in Toronto, Ontario. The authors identified $H$ pylori-positive patients by retrieval and review of histopathological reports of gastric biopsies obtained in 2007 from both the inpatient and outpatient setting. The authors specifically focused on assessing the rates of $\mathrm{H}$ pylori treatment and appropriate follow-up in adult patients. The results of this study show that initiation of eradication therapy occurred in $90 \%$ of $\mathrm{H}$ pyloripositive patients. However, only $71 \%$ of inpatients received eradication therapy compared with $96 \%$ in the outpatient setting. These results are similar to those reported in a previous Canadian study (4).

Of particular interest in this study are the potential reasons why treatment was not appropriately administered in the inpatient setting. The authors suggest that one of the major reasons treatment may not have been given in the inpatient setting was due to missed test results as patients were transferred to the outpatient setting. Indeed, only $38 \%$ of patients had pathology results available before discharge. In a cross-sectional study of two tertiary care hospitals in the United States (5), $41 \%$ of patients had test results return after discharge. In a follow-up survey of caregivers, physicians were unaware of $61 \%$ of these test results.

\begin{abstract}
'Missed' test results are an area of increasing concern and an important area for quality improvement initiatives. In a recent systematic review (6), failure to follow-up on test results of hospitalized patients ranged from $20 \%$ to $65 \%$ of tests performed, which could have significant impact on patient outcomes. The study by Yogeswaran et al highlights missed $\mathrm{H}$ pylori test results as an area of concern. However, the potential for missed test results also exists in other areas of gastroenterology such as colon cancer screening, for example. Thus, quality improvement initiatives aimed at improving histopathological test result reporting in $\mathrm{H}$ pylori infection may also be highly relevant for other potential missed test results, such as colon cancer screening, and should be an area of future focus.
\end{abstract}

\section{REFERENCES}

1. Polk DB, Peek RM Jr. Helicobacter pylori, gastric cancer and beyond. Nature Rev Cancer 2010:10:403-14.

2. Blaser M. Stop the killing of beneficial bacteria. Nature 2011;476:393-4.

3. Yogeswaran K, Chen G, Cohen L, et al. How well is Helicobacter pylori treated in usual practice? Can J Gastroenterol 2011:25:543-6

4. Nazareno J, Driman DK, Adams P. Is Helicobacter pylori being treated appropriately? A study of inpatients and outpatients at a tertiary care centre. Can J Gastroenterol 2007;21:285-8.

5. Roy CL, Poon EG, Karson AS, et al. Improving patient care. Patient safety concerns arising from test results that return after discharge. Ann Intern Med 2005;143:121-8.

6. Callen J, Georgiou A, Li J, Westbrook JL. The safety implications of missed test results for hospitalized patients: A systematic review. BMJ Qual Saf 2011;20:194-99.

Department of Pediatrics, University of Toronto; Department of Gastroenterology, Hepatology and Nutrition, The Hospital for Sick Children, Toronto, Ontario

Correspondence: Dr Nicola L Jones, Department of Gastroenterology, Hepatology and Nutrition, The Hospital for Sick Children, 555 University

Avenue, Toronto, Ontario M5G 1X8. Telephone 416-813-6185, fax 416-813-6531, e-mail nicola.jones@sickkids.ca

Received for publication August 31, 2011. Accepted September 1, 2011 


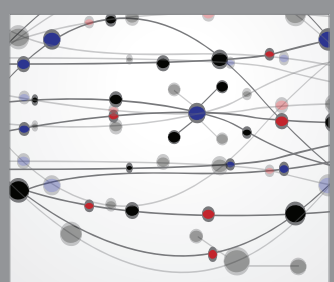

The Scientific World Journal
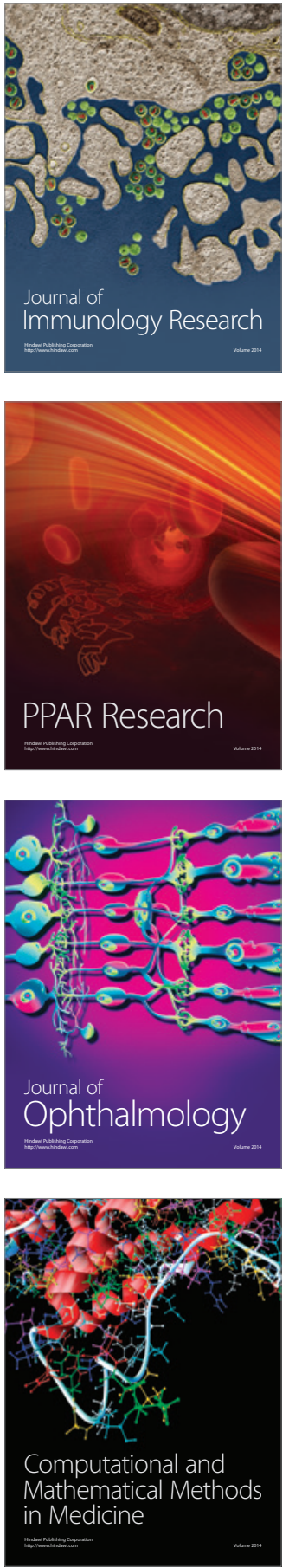

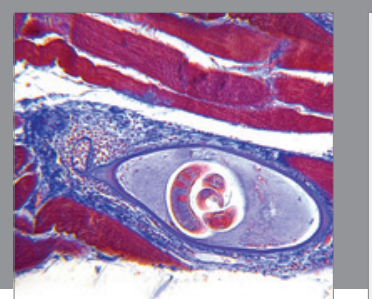

Gastroenterology Research and Practice

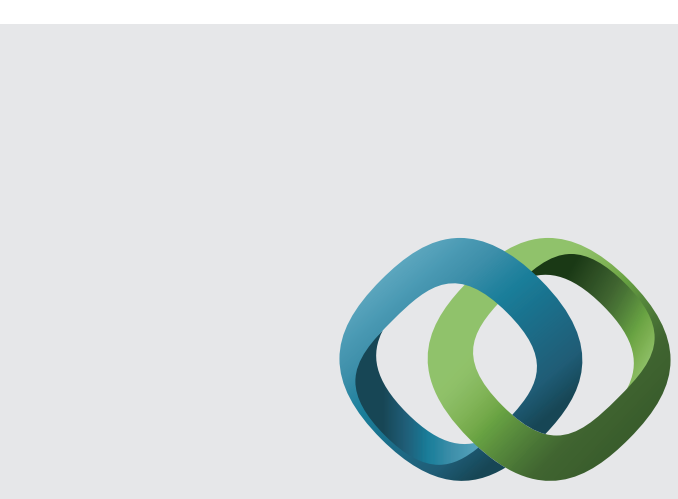

\section{Hindawi}

Submit your manuscripts at

http://www.hindawi.com
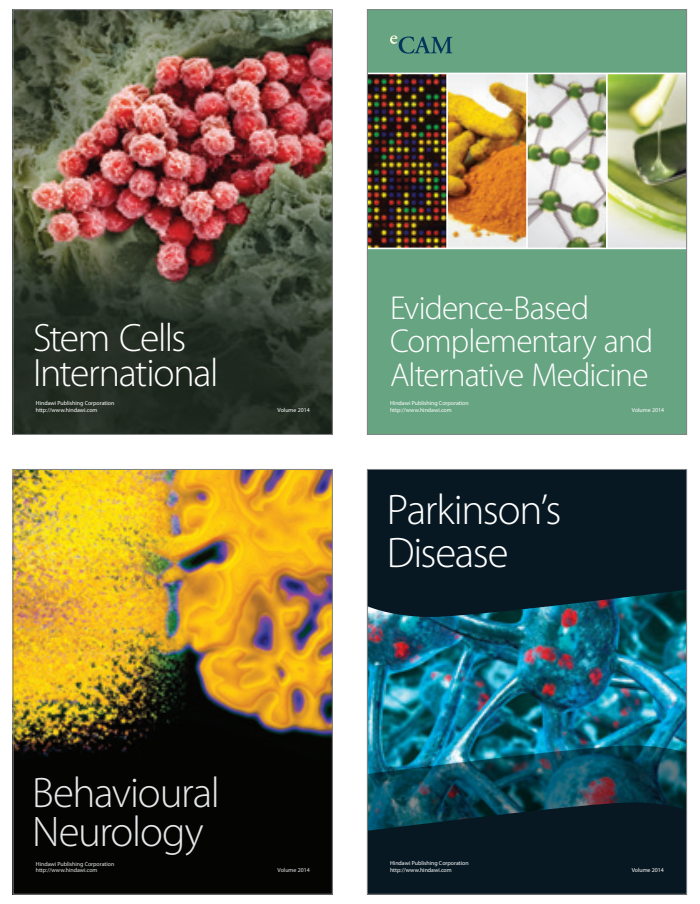
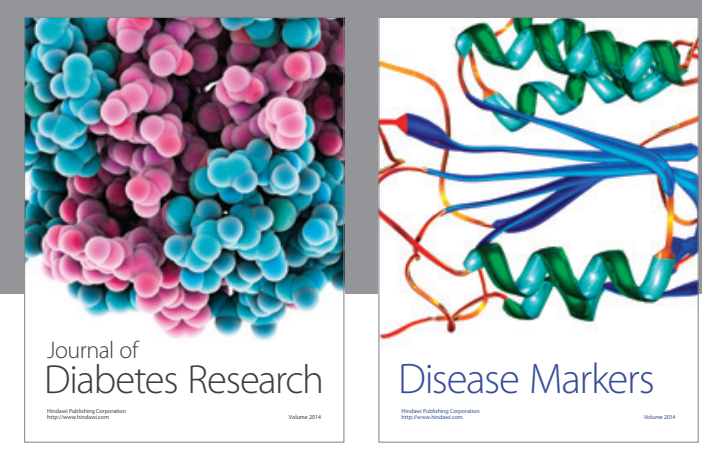

Disease Markers
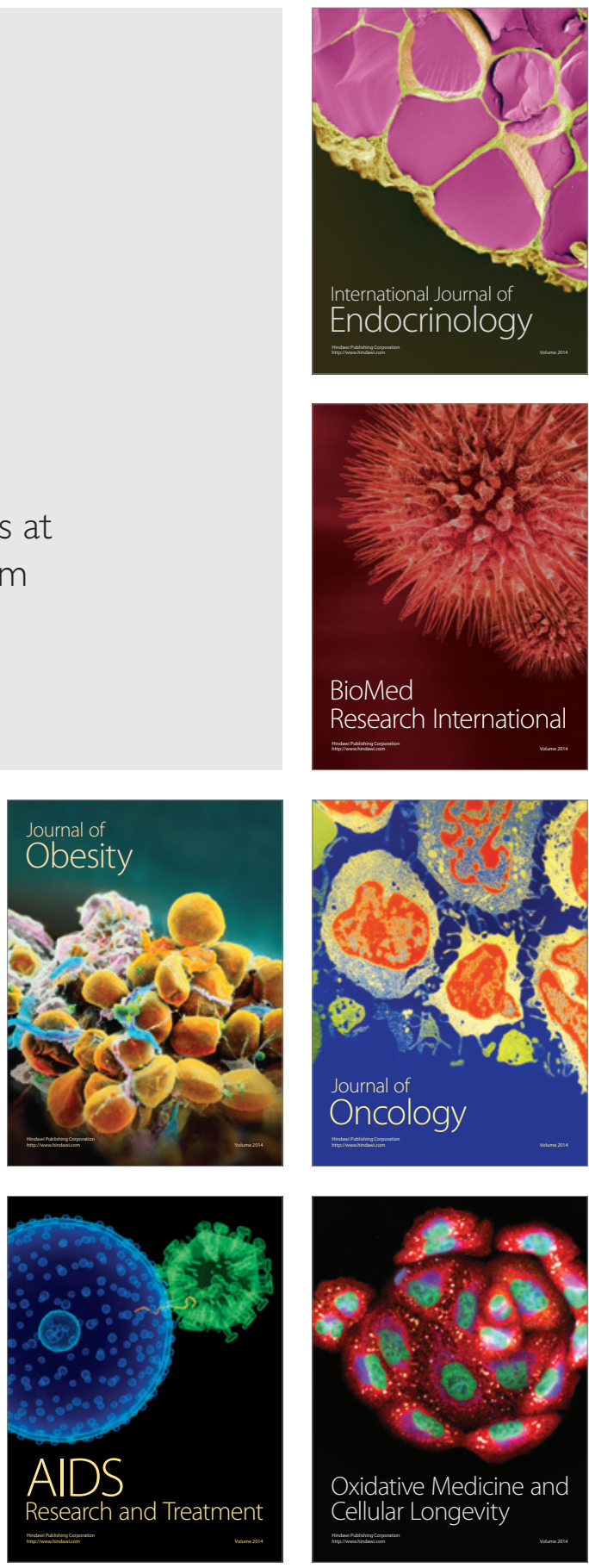